\title{
Imanência e a "arte" de interpretar em Spinoza
}

\author{
Immanence and the "art" of interpreting in Spinoza
}

JOSÉ SOARES DAS CHAGAS (iD)a

\section{Resumo}

O nosso objetivo é apresentar e discutir o método de interpretar as Escrituras desenvolvido e aplicado por Spinoza. Com efeito, já se encontrando na maturidade de seu pensamento, e envolvido na política a favor de seu pensionista Jan de Witt, chefe do partido liberal, Spinoza interrompe a sua obra suma, a Ética, para escrever o Tractatus thelogico-politicus (TTP), no qual irá defender a libertas philosofandi a partir da distinção entre os campos da razão e da fé, de maneira a associar esta à função de mera instrutora do vulgo incapaz de ascender à virtude pela via da luz natural: caminho próprio do sábio que não age pelo medo de coação ou pela recompensa da ação, mas unicamente pelo amor intelectual ao summum bonum. É por isso que realizará uma interpretação da Sacra Scriptura e a proposta de um método capaz de explicá-la por ela mesma, de maneira imanente à semelhança de como as ciências estudam a natureza.

Palavras-chave: Imanência. Interpretação. Sacra Scriptura. TTP.

\begin{abstract}
Our purpose is to present and discuss Spinoza's method of interpreting the Scriptures, developed and applied by Spinoza himself. In fact, once found in the maturity of his thinking, and involved in politics in favor of his pensioner Jan de Witt, head of the liberal party, he interrupts his prime work, the Ethics, to write the Tractatus thelogico-politicus (TTP), in which he defends the libertas philosofandi by distinguishing the fields of reason and faith, associating this last one to the function of a mere instructor of the common people, incapable of ascending to virtue by the path of the natural light, a path which is proper of the wise who does not act due to the fear of coercion or to the reward of the action, but only due to the intellectual love to the summum bonum. It is for this matter that his entire work will

\footnotetext{
a Universidade Federal do Tocantins (UFT), Palmas, TO, Brasil. Doutor em Filosofia, e-mail: jsoares007@hotmail.com
} 
become an interpretation of the Sacra Scriptura and a proposal of a method capable of explaining it by itself, immanently, in the similarity of how the sciences study nature.

Keywords: Immanence. Interpretation. Sacra Scriptura. TTP.

\section{Introdução}

A nossa reflexão aqui é de natureza teórica e aborda a crítica filosófica presente no Tratado Teológico-Político (TTP) ${ }^{1}$ à teologia por meio da discussão do seu principal fundamento: as Escrituras. Segundo Spinoza, assim como Moisés necessitou — para poder estabelecer o seu poder sobre os hebreus - afirmar-se como intérprete de Deus e como codificador das leis daquele povo, igualmente toda tentativa de fundar um Estado sobre a obediência do vulgo precisa criar, no ânimo do povo, o mesmo espírito de devoção e convencê-los de que o seu soberano lhes é superior por singular dom divino. Em se tratando do mundo judaico-cristão no qual a fonte de justificação teológica é a autoridade das Escrituras, o trabalho de fundamentação de um poder teocrático é exclusivamente hermenêutico ${ }^{2}$ e se sustenta sob a égide de uma visão mítica da natureza presente nos textos antigos. Essa cosmovisão, quando tomada irresponsavelmente pelos teólogos, torna-se instrumento de dominação, uma vez que estes assumem como certo tudo que se encontra na Bíblia sem atentarem para o fato de nela não haver conhecimento de ordem especulativa. Daí a necessidade de desconstruir este discurso supersticioso, mostrando como se deve proceder para compreender responsavelmente a

\footnotetext{
${ }^{1}$ ESPINOSA, Baruch. Tratado Teológico-Político. Trad. Diogo Pires Aurélio. 2 ed. São Paulo: Martins Fontes, 2008. (Paidéia). Como se trata de nossa fonte principal, citá-la-emos no corpo do texto sempre por meio de suas iniciais TTP, seguidas da indicação do capítulo e da página da tradução do Von Carl Gebhardt, representado pela letra G.

${ }^{2}$ A palavra Hermenêutica procede do grego (hermeneuein) e confunde-se etimologicamente com o nome do deus da comunicação Hermes. Sendo o mensageiro dos deuses, esta entidade transmite a interpretação do destino, de tal maneira que podemos conceber (hermeneuein) como a explanação acerca do destino. No nosso trabalho, utilizamos o termo "hermenêutica" no sentido de Interpretação, não simplesmente de palavras ou frases de difícil compreensão, mas no de uma releitura dos textos da Escritura, que os reconduz ao seu caráter imaginativo. Sobre este caráter hermenêutico da obra de Spinoza diz Adélio Melo: “Espinosa, enquanto hermeneuta, reflete pois o drama de qualquer hermenêutica que não se queira meramente filológica: o drama de sua inevitável inserção entre as vozes do negativo (que quer silenciar) e as vozes do positivo (que quer anunciar)": MELO, Adélio. Apresentação de Spinoza hermeneuta. In: DELEUZE, Gilles. Espinosa e os signos. Trad. Abílio Ferreira. Porto-Portugal: Rés, sd, p. 202.
} 
Escritura sem deixá-la degenerar em justificativas (interpretações!) para o poder políticoteológico perseguir os portadores de diferentes opiniões ou para declarar "guerras santas".

\section{0 poder Teológico-Político}

No ocidente cristão, desde a Idade Média até a modernidade de Spinoza (e mesmo após ele), as guerras tiveram uma motivação ou justificativa religiosa. Mesmo no fim do mundo antigo, quando o cristianismo já se impunha sobre as outras religiões, as posições dogmáticas revelavam uma posição política. É o caso dos imperadores que convocavam concílios e condenavam pensadores, a fim de manter o império coeso e os súditos obedientes e devotos. Enfim, a mensagem de salvação e amor, cerne da Escritura judaico-cristã, é constantemente transformada em discórdia e em ódio contra indivíduos, grupos e povos que sustentam uma posição doutrinal diferente da dominante (ou da que serve ao poder dominante).

Se observarmos bem em que consiste a religião ao longo da história, perceberemos nela uma roupagem cultural fruto muito mais do desejo de criar coisas novas ou de adaptar a doutrina às fantasias teológicas do que da docilidade àquilo que é ensinamento da Palavra de Deus. A Superstição reina absoluta no campo das interpretações correntes, disfarçando e camuflando as opiniões e os preconceitos sob o signo da autoridade divina. Como se tudo o que ultrapassa a compreensão humana fosse testemunha de fé autêntica e razão para acreditarmos que nas Escrituras há mistérios que, de tão profundos, não se encontram ao alcance da luz natural, fazendo-se necessária certa inspiração que a poucos é conferida. A estes caberia dizer a todos nós o que é a Vontade de Deus e o seu ensinamento. Porém, nesta atitude de arvorar-se intérprete do pensamento de Deus, o que se vê de fato é uma desonestidade em querer (a pretexto da religião) forçar os outros a aderirem a certas opiniões. $E$ isso se comprova pela incongruência entre o amor que pregam e a divisão e o desamor que espalham.

Porque, se os homens fossem sinceros quando falam da Escritura, teriam uma regra de vida completamente diferente: as suas mentes não andariam agitadas com tanta discórdia, não se combateriam uns aos outros com tanto ódio, nem manifestariam um tão cego e temerário desejo de interpretar a escritura e de inventar na religião coisas novas. [...] Todavia, a ambição e o crime foram tão longe que a religião acaba por consistir menos em obedecer aos ensinamentos do Espírito Santo que em defender humanas fantasias, e por não se traduzir pela propagação da 
caridade, mas pela disseminação das discórdias e do ódio mais feroz entre os homens, disfarçado embora de zelo divino e fervor ardente (TTP, cap. VII, pp. 114-115; G, p. 97).

As guerras santas, as cruzadas e as inquisições nunca foram propostas a título de ódio. Pelo contrário, é sempre o fervor e o zelo pela mensagem salvífica a justificativa de matar, perseguir e queimar os hereges e de se coibir as mais diversas formulações de fé consideradas contrárias ao depositum fidei. E se fosse apenas contra os de outras religiões, talvez pudéssemos (mesmo caindo em contradição) chamar de "santa" a ira motivada pelo zelo com a verdade revelada. O problema é que, mesmo no interior da religião cristã, onde todos estão sob a égide da mensagem do Cristo, há discórdias, divisão e perseguição.

O sinal dado por Jesus como critério de seu seguimento legítimo, o amor ${ }^{3}$, pouco se vê entre os que deveriam se considerar irmãos. O que mais se vê, no entanto, são calorosos debates e mútuas acusações em que se procura mais afirmar a autoridade de sua secção do que se adequar à Palavra de Deus, cujo teor, em pouco ou em nada, refere-se a rituais, cerimônias e especulações acerca da natureza divina; mas tão somente àquilo que o mais simplório homem pode entender: uma regra de vida, uma moral fundada na crença em um Deus justo e bom.

Tudo o que se acresce à substância da revelação serve apenas para aumentar a distância entre as pessoas e criar barreiras de divisão. Dito de outra forma: quanto mais se racionaliza a mensagem escriturística por meio de especulações filosóficas e se multiplicam os dogmas, mais brigas e desavenças se criam entre os cristãos; e, por conseguinte, mais se afasta da essência da Palavra de Deus em nome de fúteis invencionices teológicas disfarçadas de vontade divina.

A saída, assim, para se criar um ambiente de paz entre os homens no nosso ocidente de matriz cultural judaico-cristão, é reduzir a Escritura à sua substância, a saber, aos dogmas da crença em um único Deus providente, bondoso e justo, que recompensa os bons (aqueles que amam o seu próximo) e pune os maus (TTP, cap. VII, p. 120; G, 102).

A redução ao essencial implica uma purificação (emendatio) dos conceitos teológicos e um enfrentamento do sistema de superstição. Com efeito, as especulações em torno das Escrituras acabam por se transformar em um poder religioso sobre o vulgo ao

\footnotetext{
${ }^{3}$ Jo $13,34-35$.
} 
institucionalizar o medo e a esperança por meio dos delírios dogmáticos. Ao invés de propagar apenas que Deus ama os que defendem a justiça e o direito, os teólogos acrescentam mil reflexões sobre a providência e o sinal de eleição, procurando determinar quem são as pessoas aptas a amar, e, além disso, produzem mil elucubrações acerca da recompensa dos maus, criando fantasias acerca do destino último do homem e amedrontando o vulgo com descrições de eterno sofrimento no inferno, caso se desvie do seu domínio: do modo de vida ensinado por eles, bem como da profissão de fé também propagada pelos que se dizem autênticos intérpretes da vontade de Deus. De igual modo, promete-se um lugar na morada divina, o céu, para aqueles que reta e obedientemente se conduzirem e defenderem a ortodoxia da fé e da estrutura institucional criada para supostamente defendê-la.

Para vivermos segundo o que o "Espírito Santo" ensina e não nos subjugarmos ao discurso supersticioso dos teólogos, é necessário nos desvencilhar das discussões filosóficas em torno da revelação, mostrando que as dificuldades em se entender o texto sagrado não dizem respeito à transcendência de sua mensagem, mas ao fato de ser uma obra antiga, escrita em uma língua da qual pouco se conhece. Por isso, a purificação dos conceitos teológicos implica o estabelecimento de um método eficaz que sirva como instrumento de pesquisa capaz de nos proporcionar uma aproximação de um escrito de mensagem simples, porém culturalmente longe de nós. "Ora, para sairmos de tais confusões, libertarmos a mente dos preconceitos dos teólogos e não abraçarmos temerariamente invenções humanas como se fossem ensinamentos divinos, temos de abordar e discutir o verdadeiro método para interpretar a Escritura (TTP, cap. VII, p. 115; G, p. 98). Antes, no entanto, de apresentarmos este recurso hermenêutico formulado por Spinoza, vejamos outros modelos ou modos de interpretação, os quais só nos desviam da Palavra de Deus e nos tornam vulneráveis à superstição.

\section{0 método histórico-filológico}

Os métodos de interpretação das Escrituras expostos por Spinoza podem ser denominados de fideísta e de racionalista. O que chamamos de fideísmo refere-se ao modo de entender a fé (e, por extensão, os textos sagrados) a partir de uma consideração 
que despreza a luz natural como incapaz de desvendar os mistérios contidos nas narrativas escriturísticas. Conforme essa corrente de pensamento, as passagens truncadas e obscuras são provas de que nos deparamos com um texto para o qual são necessários uma iluminação divina e um dom especial. Ora, se os sagrados volumes tivessem uma revelação desse gênero, então deveríamos dizer que elas só foram destinadas aos fiéis; quando, na verdade, a profecia era direcionada à conversão e, por conseguinte, aos ímpios. O mesmo se diga dos apóstolos que pregaram aos pagãos. Donde se segue que a pregação deles não exige da audiência nenhuma luz sobrenatural e que esta é apenas uma maneira de alguns teólogos “confessarem as dúvidas que também nutriam, quanto ao verdadeiro sentido da Escritura num bom número de passagens [...]” (T'TP, cap. VII, p. 132; G, p.112).

Outro tipo de fideísmo é o que apela para a tradição, seja a dos fariseus, seja a dos pontífices romanos. Os primeiros estão respaldados pela lei de Moisés, que punha os sacerdotes como intérpretes legítimos do direito público da pátria ${ }^{4}$, o que era de se esperar em um Estado como o hebraico no qual a política se sustenta e se realiza no âmbito da religião ou das cerimônias e ritos. Se tal autoridade não fosse erigida para interpretar a revelação, a sociedade israelita soçobraria, uma vez que, na ausência de uma jurisprudência, o direito público se dissolveria em direito individual no qual cada um, apoiado na sua liberdade, interpretaria a Lei a seu bel-prazer.

Já no caso dos papas, esta pretensa autoridade advinda de uma transferência do poder legado ao pontífice hebreu para o pontífice cristão por meio do Cristo (o messias que inaugura o novo Israel) não parece muito clara. Com efeito, Jesus não fundou uma religião, coisa que parece muito clara pelo fato de haver vivido segundo as leis de sua pátria (sem querer alterá-las ou aboli-las) ${ }^{5}$; e, além do mais, a sua pregação não visava tanto a atos externos como à atitude interior, a saber, autenticidade de ânimo e simplicidade. Acrescente-se a este argumento, por si mesmo já suficiente, a história dos papas cheia de hereges (ou seja, de homens que interpretaram a Palavra de Deus fora da ortodoxia) e de devassos 6 .

\footnotetext{
${ }^{4}$ Dt $17,11$.

${ }_{6}^{5}$ Mt 5, 17s.

${ }^{6}$ Para a compreensão do verdadeiro sentido das passagens das Escrituras, deve-se abrir mão dos prejuízos ou de conteúdos doutrinais pré-estabelecidos. Como é o caso da suposta autoridade e tradição, por parte dos católicos; e de uma suposta inspiração sobrenatural, por parte dos protestantes.
} 
Em uma direção contrária à atitude fideísta de compreensão dos escritos sagrados, encontra-se o racionalismo de Maimônides. Este teólogo e filósofo judeu nascido em Córdoba, em meados do século XII d.C, pensa o mundo e a sua fé influenciado pela onda aristotélica trazida à baila no ocidente pelos Árabes. Em sua concepção de verdade estão presentes as causas que determinam os fenômenos naturais, podendo ser alcançadas somente pelos princípios derivados da luz natural ou das definições das coisas e das causas primeiras. Ora, nas Escrituras não se encontram senão relatos indemonstráveis e impossíveis de serem investigados pela razão. Como, então, se pode pretender explicar os milagres e os relatos mediante um método que procura compreendê-los racionalmente? Para o venerável médico e rabino judeu, a resposta a essa indagação dá-se pela verificação da natureza polissemântica das passagens escriturísticas, as quais só poderão apresentar o seu sentido verdadeiro quando o intérprete demonstrar, pela luz natural, o real significado daquilo que é apresentado no texto. O problema deste procedimento hermenêutico se encontra na incongruência em afirmar algo de um texto sem antes entender o seu sentido. A verdade vem de fora, ou seja, primeiro se verifica se algo é plausível ou não ao lume natural e depois se atribui à Escritura, fazendo com que esta acabe por dizer, muitas vezes, aquilo que nunca pretendeu. Por meio de processos analógicos e metafóricos o hermeneuta empenha toda a sua criatividade de maneira a fazer parecer que o texto está a dizer aquilo que a filosofia demonstra e ensina.

A ousadia de Maimônides, em adequar o conhecimento racional à revelação, é tão pretensiosa que chega a beirar o absurdo de afirmar que devemos rejeitar o sentido de um texto sagrado, caso esteja evidente que ele repugna a razão. Como na passagem do More Nebuchim citado por Spinoza (TTP, cap. VII, p. 133-134; G, p. 113), no qual o filósofo judeu refuta a eternidade do mundo não porque ela esteja em contradição com o texto, mas antes por não poder ser demonstrada à semelhança das afirmações de que Deus é corpóreo e outras que se encontram na Escritura.

A maneira de interpretar de Maimônides subverte a função das Escrituras que é a de educar o povo na obediência e na piedade. Torna um livro de caráter essencialmente popular em uma obra filosófico-científica fora do alcance do comum dos homens para os quais é desnecessária toda a especulação racional para se conduzir moralmente na vida. Se a opinião do teólogo judeu estivesse correta, então reduziríamos os textos dos sagrados códices às opiniões e preconceitos do intérprete ou à sua filosofia. Aliás, seria necessário 
erigir um novo tipo de sacerdócio ou pontificado (TTP, cap. VII, p. 135; G, p. 114), o dos filósofos, os quais seriam indispensáveis para estabelecer a verdade à qual os textos deveriam adequar-se mediante analogia ${ }^{7}$.

Enquanto o grande dogmático apontado por Spinoza é o judeu Maimônides, a referência judaica do ceticismo ${ }^{8}$ é Judas Alpakhar, a quem é dirigido um elogio por haver atentado para a necessidade de buscar o sentido da Escritura de maneira imanente, ou seja, nela mesma. "É essa em resumo, a opinião de Alpakhar, a quem, aliás, eu presto homenagem, porquanto pretende explicar as Escrituras pelas Escrituras" (TTP, cap. XV, p. 225; G, 181). Segundo este cético, sempre que se verificasse uma contradição entre o texto sagrado e a filosofia, não se deveria procurar sanar o problema por meio de uma interpretação metafórica da Tanach; pelo contrário, dever-se-ia procurar imanentemente o significado, observando outras passagens referentes ao mesmo assunto e que apresentassem expressamente o sentido. Uma vez encontrada a maneira correta de se entender certos termos e expressões, aí sim se procederia de maneira alegórica, procurando explicar o texto obscuro, como se lá estivesse implicitamente o que se averiguou em outro lugar.

Daí por que o nosso autor, após haver rendido homenagem ao honorável rabino, teve de lhe fazer ressalvas e censurá-lo. "Surpreende-me, no entanto, que um homem dotado de razão se esforce por destruí-la. [...] Decididamente, é impossível não ficarmos espantados quando querem submeter a razão, o maior dos dons, essa luz divina, à letra morta que a malícia humana pode ter falsificado!" (TTP, cap. XV, p. 225; G, p. 181-182). A oposição feita por Spinoza a Alpakhar deve-se aos princípios decorrentes do ceticismo, a saber: 1 . Tomar como verdadeiro tudo o que está escrito na Tanach; 2. Negar qualquer contradição. Quanto ao primeiro ponto, deve-se dizer que a verdade é do âmbito do

\footnotetext{
${ }^{7}$ Ora, como por meio de comparações e metáforas se pode forçar o texto a dizer qualquer coisa, o método racionalista e o fideísta se tornam nocivos na medida em que podem ser usados para multiplicar formulações dogmáticas e institucionalizar a fé por meio de ritos e cerimônias determinados; enfim, na medida em que podem justificar um poder teológico e aumentar a distância entre determinadas maneiras de entender a religião e de estilos de vida daí decorrentes. A fim de evitar que a mensagem simples de amor ao próximo se transforme em ódio e divisão, é preciso considerar a natureza da Escritura, qual seja: uma mensagem que visa a despertar a devoção e a obediência mediante relatos e revelações, que se adéquam não à mente dos filósofos, mas às opiniões e aos preconceitos tanto dos escritores, como da audiência destinada.

${ }^{8} \mathrm{O}$ sentido de ceticismo utilizado por Spinoza refere-se à "descrença" na razão e neste sentido equivale ao que convencionamos chamar, para fins didáticos, de fideísmo.
} 
universo da filosofia, que investiga a "história da natureza" por meio das notiones communes; já a Teologia procura explicar a Palavra de Deus por meio da "história da Escritura". E, neste sentido, o preclaro rabino estaria correto se não tivesse confundido o sentido com a verdade.

Com efeito, quando se lê responsavelmente a Bíblia, busca-se explicar o sentido das palavras, dos profetas e dos relatos extraordinários, sem interferência do conhecimento racional ou de nossas opiniões particulares. Porém, uma vez que nós o encontramos, não precisamos aderir àquilo que repugna ao conhecimento racional, ao contrário, devemos recorrer ao juízo, à razão, para sabermos se podemos dar sem reservas a nossa aquiescência. Do contrário, deveríamos dizer que só como loucos ou néscios poderíamos nos fazer fiéis, acreditando em "preconceitos populares de tempos antigos" (TTP, cap. XV, p. 223; G, p. 180).

Quanto ao segundo ponto, em que Judas Alpakhar diz não haver nenhuma passagem em que ao afirmar algo seja depois negado, Spinoza responde que só por muita falta de atenção se pode dizer tal coisa. Ora, quem não vê que nas Escrituras há enunciados contraditórios? Haja vista Salomão dizer ${ }^{9}$ de Deus que ele não habita lugar nenhum na terra; e em Êxodo, capítulo XIX, versículo XX, claramente se falar que ele desceu sobre o monte Sinai. Certamente, o rabino diria que é preciso considerar o sentido implícito como sendo superior ao explícito; mas o que isso importa "[...] se o que está implícito é claro e se tanto a natureza desta passagem quanto seu contexto não são passíveis de interpretação metafórica?” (TTP, cap. XV, p. 228; G, p. 184).

Ora, o ceticismo de Alpakhar busca uma conciliação entre a fé e a razão de tal modo que precisaríamos nos tornar fundamentalistas. Por isso, ao bem da religião e do Estado, tal tese (bem como a dogmática) deve ceder lugar ao imanentismo investigativo pelo qual se respeita ambas as esferas como autônomas tanto no seu objeto quanto no seu fundamento. Entretanto, deve-se ressaltar que, embora a filosofia e a teologia não pertençam à mesma esfera do saber, elas não se contradizem, pois a mesma “[...] palavra de Deus que está nos profetas concorda absolutamente com a palavra de Deus que se faz ouvir em nós" (TTP, cap. XV, p. 231; G, p. 186).

\footnotetext{
${ }^{9} 1$ Rs $8,27$.
} 
Donde se segue que os textos sagrados estão no nível do comum dos homens e que se não o compreendemos, não é devido a nenhum sentido transcendente ao texto, todavia é por causa da língua, que não foi conservada e que não nos é familiar. Assim, o único sentido possível e legítimo é o literal, consistindo todo o método de interpretação proposto por Spinoza em buscá-lo. Para isso, deve-se proceder como na investigação da natureza ${ }^{10}$.

[...] o método de interpretar a Escritura não difere em nada do método de interpretar a natureza; concorda até inteiramente com ele. Na realidade, assim como o método para interpretar a natureza consiste essencialmente em descrever a história da mesma natureza e concluir daí, com base em dados certos, as definições das coisas naturais, também para interpretar a Escritura é necessário elaborar a sua história autêntica e, depois, com dados e princípios certos, deduzir daí com legítima conseqüência o pensamento de seus autores. [...] Donde, a regra universal a seguir na sua interpretação é a de não lhe atribuir outros ensinamentos além dos que tenhamos claramente concluído pela sua história (TTP, cap. VII, p. 115-116; G, p. 98-99).

A grande meta ensejada pela interpretação das Escrituras consiste em deduzir a mensagem pretendida pelo autor aos seus coetâneos. Daí a necessidade de se proceder como se fosse um pesquisador da natureza a quem cabe tirar conclusões simplesmente daquilo que ela própria oferece. Ora, mas como nela não há equações de suas leis explícitas em suas manifestações fenomênicas, faz-se necessário observar com cautela a frequência com que se processam as ocorrências naturais para só depois tornar claro o que estava implícito.

A atitude filosófica aqui se reduz à descrição da história do próprio objeto e não a uma consideração externa a partir de princípios estranhos ${ }^{11}$. De igual modo, na

\footnotetext{
${ }^{10} \mathrm{O}$ método de investigação da natureza é inaugurado por Bacon, para quem o único caminho seguro a seguir no conhecimento dos fenômenos seria o da reconstituição da "história natural", consistindo em recolher "[...] os axiomas dos dados dos sentidos particulares, ascendendo contínua e gradualmente até alcançar, em último lugar, os princípios da máxima de generalidade. Este é o verdadeiro caminho, porém ainda não instaurado" (BACON, Francis. Novum Organum ou verdadeiras indicações acerca da natureza. Tradução e notas de José Aluysio Reis de Andrade. São Paulo: Nova Cultural, 1997, aforisma XIX, p. 36).

${ }^{11} \mathrm{O}$ método de interpretação da Bíblia não é a aplicação prática da filosofia aos textos, mas é uma abordagem em que a revelação é tratada como pertencendo ao campo da natureza naturada e, portanto, passível de ser interpretada mediante a manifestação de seus dados empíricos ou de seus "sinais", que não são mais do que efeitos da forte imaginação dos profetas e dos escritores sagrados. "Il s'agit de recueillir um ensemble de faits pour délimiter ensuite, par une série de conséquences legitimes, um certain nombre de concepts bien fondés. C'est la méthode experimenta, l'induction baconienne appliquée à l'exégèse. II s'agit encore d'une méthode rationnelle, puisqu'elle met em ouvre une raison critique, mais elle diffère de la recherché philosophique par la spécificité de son domaine. La révélation étant, aux yeux de Spinoza, une révélation empirique, une révélation en images [...] elle ne peut être saisie que comme un donné demandant à être analysé" (AUWERS, Jean-Marie. L'interprétation de la Bible Chez Spinoza. Présupposés philosophiques. Revue théologique de Louvain, 21, 1990, p. 202).
} 
interpretação da Escritura cumpre analisá-la cuidadosamente, utilizando-a como critério dela mesma ${ }^{12}$. Em outras palavras, na busca do significado das passagens dos sagrados códices o fundamental é deduzir o significado somente por certa norma linguística, deixando de lado a questão de saber se ela repugna a luz natural ou não. Tal princípio se desdobra em tarefas básicas. A primeira delas diz respeito ao estudo das línguas ${ }^{13}$ com as quais foi escrita a Bíblia bem como de suas propriedades, para tornar possível determinar todos os sentidos que cada passagem possa ter.

Feita a consideração do Hebraico e do Grego, o passo seguinte é reduzir as opiniões dos hagiógrafos aos pontos principais, tomando nota das que se afigurarem obscuras ou contraditórias. Não devemos nos preocupar se em tais passagens há um contrassenso racional, pois o que importa na interpretação é a inferência do sentido e não da verdade dos relatos ou das profecias, o que significa dizer que as respostas às dificuldades de entendimento devem ser resolvidas em um raciocínio cuja norma seja a própria Escritura.

Spinoza dá o exemplo da expressão "Deus é fogo" dizendo que não se pode repugnar tal afirmação e elaborar uma explicação metafórica simplesmente porque é contrária à razão. O procedimento correto é passar a vista sobre toda a vida e palavras do grande profeta dos hebreus descritas nos sagrados códices e observar as suas ideias e preconceitos realizando uma síntese delas. Também se deve verificar como é empregada a palavra "fogo" em outras passagens da Escritura. Concluída esta pesquisa, saber-se-á que

\footnotetext{
${ }^{12}$ Ao abandonar os prejuízos dos teólogos, Spinoza parece aderir a uma interpretação racional dogmática; entretanto, ele assume o princípio do sola scriptura do protestantismo. Como explicar este paradoxo? Uma resposta plausível e verossímil é a de que era mais importante para o nosso filósofo, livrar-se da peche de ateu do que confundir o seu método de leitura com o da Reforma. “[...] considero que lo más probable es que Spinoza considerase más importante desvincularse de toda línea dogmática [...], que insistir en su distancia respecto de las iglesias reformadas. Al fin y al cabo, el propio Spinoza podía temer, y quizá no sin razón, que su intervención tendería a encuadrarse en las filas del racionalismo dogmático o ateo, mas bien que entre las líneas de fuga heteredoxas que nacían del protestantismo. Recuérderse a este respecto que responder a la acusación de ateísmo se hallaba entre las principales motivaciones [cf. Ep XXX] que Spinoza menciona para redacción del TTP" (FORTE, Juan Manuel. Historia y filosofía en la hermenéutica bíblica de Spinoza. In: Anales del seminario de Historia de la Filosofia, v. 25, 2008, p. 316).

${ }^{13}$ Quanto à preocupação com a língua e sua natureza, deve-se destacar que nos foi legado por Spinoza uma gramática do hebraico (SPINOZA, Baruj. Compendio de gramatica de la lengua hebrea. Madrid: Trotta, 2005). A propósito, consultar o primeiro capítulo de CHAUÍ, Marilena. Da realidade sem mistérios aos mistérios do mundo. São Paulo: Ed. Brasiliense, 1981, que procura discutir a relação entre a Gramática Hebraica e o imanentismo em Spinoza.
} 
Moisés não admitia representação de Deus sob nenhuma forma material, donde se segue que repousa nesta expressão um sentido metafórico, qual seja: o de "ciúme", conforme se verifica em outro lugar da Escritura ${ }^{14}$. Em síntese, embora antropomórfica e imagética, conservar-se-á o sentido extraído com base unicamente nos textos sagrados.

A referência a Moisés nos dá a indicação de um terceiro procedimento exegético, a saber: perpetrar um levantamento de todos os dados relativos ao autor, à época em que foi escrito e aos destinatários originais. Com essa pesquisa, ter-se-á segurança quanto à intenção do redator e se poderá determinar o sentido dado às suas palavras bem como nos precaverá de não tomar qualquer ensinamento circunstancial (voltado para um grupo específico, em um dado momento) como se fosse doutrina eterna, a qual não se poderia revogar.

Além da formação do livro, devemos nos ater à história posterior da obra. Importa, assim, saber tudo sobre as voltas que deu cada livro, ou seja, por quais mãos passou, quantas versões recebeu, se houve alterações e adulterações, se alguém procurou consertar essas modificações; enfim, descrever todas as vicissitudes da obra até chegar a nossas mãos, procurando saber, inclusive, por que razões foi admitido no cânon.

Descrita a história das Escrituras por meio do método que podemos chamar de histórico-filológico ${ }^{15}$, assumimos o compromisso para uma interpretação responsável de admitir como mensagem dos autores da Escritura somente aquilo que decorre claramente dos próprios textos ${ }^{16}$. Só assim poderemos com segurança "[...] nos cingir à investigação do pensamento dos profetas e do Espírito Santo" (TTP, cap. VII, p. 120; G, p. 102).

\footnotetext{
${ }^{14}$ Jo $31,12$.

${ }^{15}$ Spinoza vai ser o primeiro a sistematizar o método de interpretação que, hodiernamente, é o mais utilizado nos meios acadêmicos. Malgrado isso estar muito claro, no capítulo VII do TTP, a história da exegese e a hermenêutica bíblica não o reconhecem como precursor do Método Histórico-Crítico. O meio eclesiástico dá esta paternidade a Richard Simon, o qual teve como único mérito questionar a autoria do Pentateuco por parte de Moisés: Cf. PONTIFÍCIA COMISSÃO BíBLICA. A interpretação da Bíblia na Igreja. São Paulo: Paulinas, 1994, p. 37-38. Trabalho este muito limitado se comparado ao que o nosso filósofo realizou desde o capítulo VII até o XI do TTP.

${ }^{16}$ Para um cotejamento do método spinozano com a exegese atual do meio acadêmico, indicamos, além das introduções aos livros das Bíblias já mencionadas, os seguintes Manuais: SILVA, Cássio Murilo Dias da (com a colaboração de especialistas). Metodologia de exegese bíblica. São Paulo: Paulinas, 2000; WEGNER, Uwe. Exegese do Novo Testamento. Manual de metodologia. 4 ed. São Leopoldo: Sinodal/São Paulo: Paulus, 1998; e SCHNELLE, Udo. Introdução à exegese do Novo Testamento. Trad. Werner Fuchs. São Paulo: Loyola, 2004.
} 
Não podemos nos esquecer, no entanto, de observar outro procedimento da investigação natural, qual seja, procurar determinar primeiro o que há de mais universal para só depois buscar aquilo que daí decorre. No caso das passagens de ensinamento moral, cumpre partir do que está em todos os navis, a saber, a crença em um Deus bom e veraz e a necessidade de amar a fim de imitá-lo e conquistar a recompensa oferecida por Ele àqueles que assim procedem.

As passagens obscuras, referentes a atos particulares e exteriores, embora decorrentes da doutrina universal, devem ter o seu significado determinado a partir da acareação textual, como no seguinte ensinamento de Jesus: “àquele que te bateu na face direita dá também a outra" ${ }^{17}$. No cotejamento com o restante do evangelho, fica claro o significado dessa passagem, a qual não depõe contra justiça do Estado, mas tão somente exorta aqueles que vivem em uma sociedade corrupta, em pleno ocaso, a perdoarem as injúrias dos ímpios, haja vista estarem fadados à punição pelas próprias circunstâncias de derrocada do sistema que os defende.

Já em relação aos textos de teor especulativo sobre os quais se encontram as mais ardorosas controvérsias, não adianta buscar o significado de enunciados de um profeta em outro, pois cada um conservou e adaptou as revelações aos seus preconceitos. Entretanto, o processo de interpretação segue os mesmos passos, quais sejam: inferir da própria Escritura o que há de mais universal, a saber, a natureza da profecia, da revelação e dos milagres. E, só depois, investigar a opinião de cada navi em particular e da mensagem por detrás de cada milagre e narrativa. Tomadas todas essas precauções e seguindo o método histórico-filológico, estaremos de posse da essência da revelação e não daremos margem à superstição e à consequente multiplicação dos dogmas. Além disso, encontrar-nos-emos seguros do sentido das Escrituras e não careceremos de nenhuma outra autoridade, a não ser a dos próprios textos sagrados.

\footnotetext{
Apresentamos assim o modo de interpretar a Escritura e demonstramos, ao mesmo tempo, ser esta a mais firme e até a única via para se procurar o seu verdadeiro sentido. Admito, evidentemente, que esteja mais seguro de qual é esse sentido alguém que tenha recebido, se caso existe alguém assim, a genuína tradição ou a verdadeira explicação dos próprios profetas, como pretendem os fariseus, ou então aqueles que têm o Pontífice que é infalível a interpretar a Escritura, como alardeiam os católicos romanos. Mas como não podemos estar certos, nem dessa tradição, nem da autoridade do papa, também não se pode fundamentar nenhuma certeza sobre tais bases (TTP, cap. VII, p. 123; G, p. 105).
}

\footnotetext{
${ }^{17}$ Mt 5, 17.
} 
Assim, aquilo que não se pode determinar simplesmente pela própria Escritura não adianta buscar alhures. Ora, se há passagens obscuras e de difícil interpretação não se deve a nenhum significado transcendente; antes é por falta do conhecimento da língua e da história dos volumes sagrados, as quais foram negligenciadas pelos judeus antigos. Disso decorrem as dificuldades que enfrentamos na interpretação dos textos da Bíblia e que nos impedem de afirmar com toda a certeza o correto sentido de cada passagem.

Um grande obstáculo diz respeito à natureza da língua. Não nos foi legada nenhuma gramática, semântica ou retórica, o que dificulta a nossa compreensão do modo peculiar dos hebreus. Além do mais, o hebraico guarda certas especificidades, tais como: o verbo, que possui uma única forma para mais de um tempo; a proximidade de sonoridade de certas letras, que acabam por influir no significado de uma palavra; os múltiplos sentidos de um único termo; e, some-se a tudo isso, o fato desta língua ser escrita originalmente sem vogais e sem sinais ortográficos. Tudo isso só reforça a necessidade de uma leitura imanente à Escritura, na qual o processo social, cultural e linguístico seja a égide de uma compreensão da mensagem de obediência e amor ensinada pelos profetas e pelas narrativas sagradas.

\section{Considerações finais}

Assim, vê-se claramente que as dificuldades encontradas na interpretação das Escrituras se devem ao nosso desconhecimento acerca da literatura hebraica e não a uma pretensa verdade escondida, como quer a Superstição ávida de fantasias e de mistério. É por isso que se faz necessário realizar uma emendatio na fonte dos argumentos teológicos a partir da determinação do que seja a Palavra de Deus e de uma leitura panorâmica das Escrituras, perpetrada segundo o princípio deste método histórico-filológico, o qual exige de nós uma fidelidade ao próprio texto, ou seja, uma leitura imanente, sem medo de encontrar contradições, adulterações ou mesmo sem temor de nos desviarmos das explicações ortodoxas (ou das opiniões correntes). Tudo isso se faz necessário para a abordagem teológica não transformar a fé em superstição e a religião em tirania teocrática (e em guerra fratricida!). 


\section{Referências}

AUWERS, J.-M. L'interprétation de la Bible Chez Spinoza. Présupposés philosophiques. Revue théologique de Louvain, 21, 1990.

BACON, F. Novum Organum ou verdadeiras indicações acerca da natureza. Tradução e notas de José Aluysio Reis de Andrade. São Paulo: Nova Cultural, 1997.

CHAUÍ, M. Da realidade sem mistérios aos mistérios do mundo. São Paulo: Brasiliense, 1981.

ESPINOSA, B. Tratado Teológico-Político. Trad. Diogo Pires Aurélio. 2 ed. São Paulo: Martins Fontes, 2008. (Paidéia).

FORTE, J. M. Historia y filosofía en la hermenéutica bíblica de Spinoza. In: Anales del seminario de Historia de la Filosofia, v. 25, 2008.

MELO, A. Apresentação de Spinoza hermeneuta. In: DELEUZE, Gilles. Espinosa e os signos. Trad. Abílio Ferreira. Porto-Portugal: Rés, sd.

PONTIFÍCIA COMISSÃO BÍBLICA. A interpretação da Bíblia na Igreja. São Paulo: Paulinas, 1994.

SCHNELLE, U. Introdução à exegese do Novo Testamento. Trad. Werner Fuchs. São Paulo: Loyola, 2004.

SILVA, C. M. D. Metodologia de exegese bíblica. São Paulo: Paulinas, 2000.

SPINOZA, B. Compendio de gramatica de la lengua hebrea. Madrid: Trotta, 2005.

WEGNER, U. Exegese do Novo Testamento. Manual de metodologia. 4 ed. São Leopoldo: Sinodal/São Paulo: Paulus, 1998. 